\title{
Efficacy of Acupuncture for the Treatment of Fibromyalgia: Systematic Review and Meta-Analysis of Randomized Trials
}

\author{
Eva Martin-Sanchez ${ }^{\mathrm{a}}$ Eva Torralba ${ }^{\mathrm{a}}$, Elena Díaz-Domínguez ${ }^{\mathrm{a}}$, Andrés Barriga ${ }^{\mathrm{b}}$ and \\ Jose Luis R. Martin ${ }^{*}, \mathrm{a}, \mathrm{c}$ \\ ${ }^{a}$ Department of Clinical Research, Castile-La Mancha Health Research Foundation (FISCAM), Toledo, Spain \\ ${ }^{b}$ Department of Orthopedic Surgery and Traumatology, National Hospital for Paraplegics. Toledo, Spain \\ ${ }^{c}$ Department of Applied Research. National Hospital for Paraplegics, Toledo, Spain
}

\begin{abstract}
Objective: The study sought to ascertain the effectiveness of acupuncture as a treatment for fibromyalgia
Materials and Methods: The following electronic databases were searched: PubMed; The Cochrane Library (CENTRAL); EMBASE; CINAHL; and Pascal Biomed (last date of search: January 2008). We analyzed pain intensity and patient withdrawals prior to termination of the study. A meta-analysis was performed, and a weighted global effect obtained using the inverse of variance.

Results: This review covered a total of 6 studies (323 subjects). No statistically significant differences were observed in terms of pain intensity (VAS): 0.02 (-0.24 a 0.28$)$ or withdrawals: RR 0.91 (0.53 a 1.58)

Conclusion: This systematic review found no evidence of benefit resulting from acupuncture versus placebo, as a treatment for fibromyalgia.
\end{abstract}

Keywords: Acupuncture, fibromyalgia, systematic review, meta-analysis.

\section{INTRODUCTION}

Fibromyalgia is a disorder that results in generalized chronic pain for sufferers. Its principal symptoms are the appearance of a number of tender points around the body, stiffness in the muscles, tendons and surrounding soft tissue, weakness, sleep disorders, disturbances in bowel function, rigidity in the extremities, and depressive episodes accompanied by anxiety crises [1]. It affects $0.5 \%-5 \%$ of the general population, and is more common among middleaged women than among men [2]. The complaint can go so far as to render sufferers incapable of working and leading a normal life, and thereby affect their quality of life.

Fibromyalgia-related pain is treated with analgesics, antidepressants, physical exercise, relaxation techniques, and educational programs [3]. The effectiveness of supervised training with aerobic exercises has also been demonstrated [4], but there is no unanimous protocol for treating the condition. While antidepressants have shown themselves to be effective in the treatment of symptoms [5], the best recommendations available are based on the opinions of committees of experts. One of the alternative treatments used to ameliorate the symptoms is acupuncture, though the various studies which have addressed acupuncture and fibromyalgia to date, have failed to furnish solid evidence of its efficacy [6].

*Address correspondence to this author at the Castile-La Mancha Health Research Foundation (FISCAM), Edificio Bulevar, C/ Berna 2, Local 0-2, 45003 - Toledo, Castilla-La Mancha, Spain; Tel: +34 925281144; Fax: +34 925281149; E-mail: jlrmartin@jccm.es

\section{MATERIALS AND METHODS}

\section{Identification of Studies}

To identify studies, a search was made of the following electronic databases, namely, PubMed, The Cochrane Library (CENTRAL), EMBASE, CINAHL, and Pascal Biomed, using the following key words: "Fibromyalgia"; "Acupunture"; and "Chronic pain". The last date of search was January 2008.

\section{Studies}

For inclusion purposes, we selected randomized controlled trials (RCTs) that compared acupuncture/electroacupuncture against a sham technique in subjects with diagnosis of fibromyalgia.

\section{Outcome Measure}

The principal outcome measure was intensity of pain measured on a visual analog scale (VAS). Account was also taken of subject withdrawals prior to termination of the study.

\section{RESULTS}

The above search strategy located a total of 59 references that linked acupuncture/electroacupuncture to fibromyalgia. On the basis of these references, 33 abstracts with potential inclusion criteria were initially identified; of these 33 studies, only six met the selection criterion established in the initial objectives of this review [7-12] (Fig. 1). The remaining 27 were excluded for a number of reasons: 3 were ongoing at the date of analysis and had no data available for our study, 20 failed to meet the requirement of randomised 


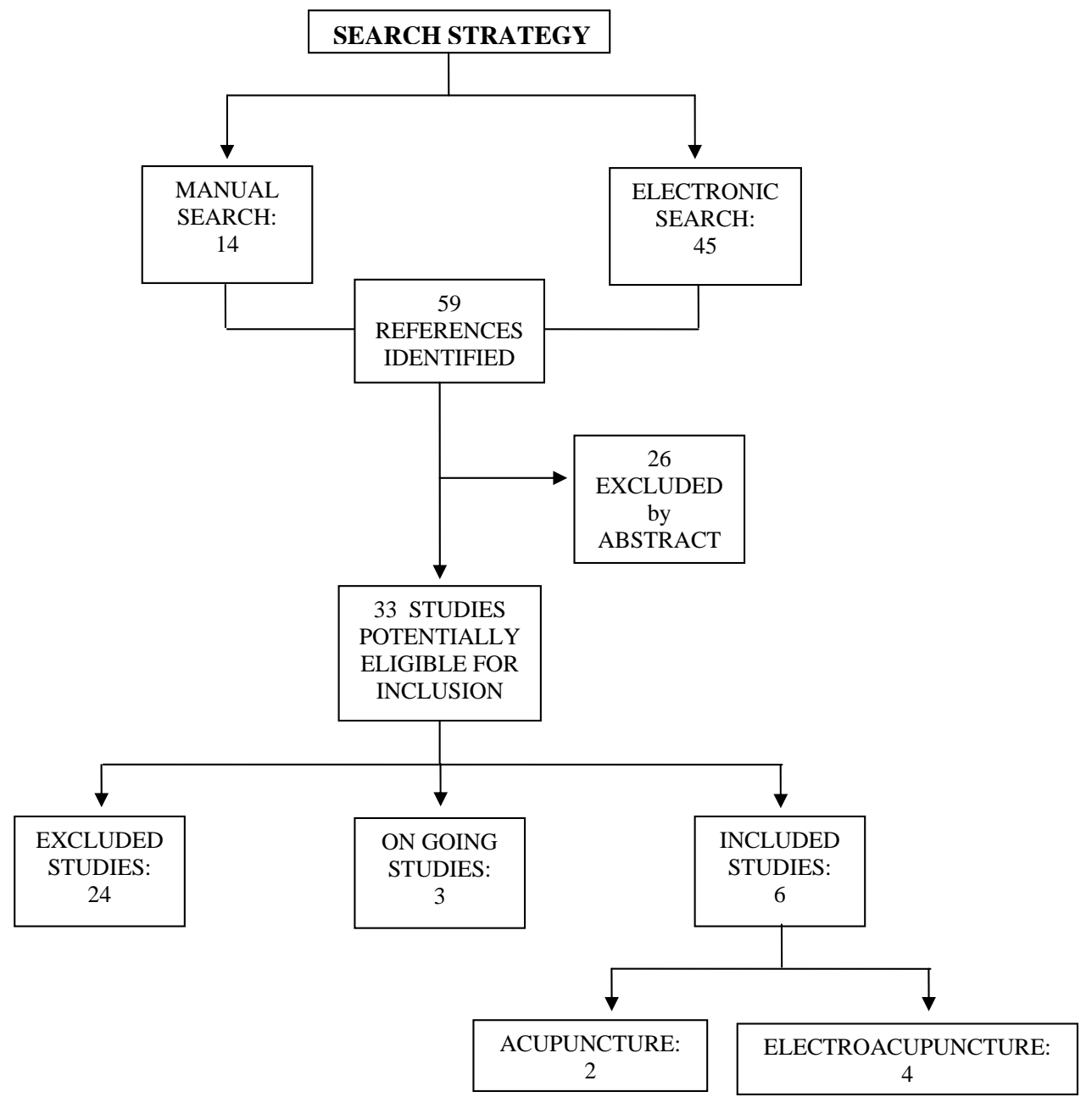

Fig. (1). Flow of studies through selection process.

clinical trial methodology, 1 displayed repeated data, 2 were conducted on healthy volunteers and 1 without a sham control group.

\section{Study Population}

The clinical trials included in this review were conducted on adult ambulatory populations, mean age 48.84 years (SD $=2.85$ ). For determination of fibromyalgia, all studies used American College of Rheumatology diagnostic criteria [1]. Study intervention time ranged from 2 to 13 weeks. As the placebo method, different types of sham techniques were used, namely: non-penetrating simulated acupuncture at acupuncture points; acupuncture with insertion at nonacupuncture points; or acupuncture at acupuncture points not suited for fibromyalgia (Table 1).

\section{Meta-Analysis}

Insofar as pain intensity was concerned, pooled analysis of 4 studies with a combined sample of 257 subjects indicated a non-statistically significant standardized mean difference (SMD) between groups from baseline, of 0.02 (95\% CI -0.24 to 0.28 ) (Fig. 2A).

With respect to withdrawal prior to termination of the study, pooled analysis of five studies with a combined sample of 323 subjects yielded a relative risk (RR) of 0.91
$(0.53,1.58)$, with no statistically significant differences (Fig. 2B).

In both the above meta-analyses considerable intra-study homogeneity was in evidence: $\mathrm{p}=0.41 ; \mathrm{I}^{2}=0 \%$ for intensity of pain and $\mathrm{P}=0.89 ; \mathrm{I}^{2}=0 \%$.

\section{DISCUSSION}

Based on currently available data, this systematic review found no evidence of the effectiveness of acupuncture in the treatment of fibromyalgia.

This review highlights the fact that fibromyalgia sufferers who undergo a therapeutic intervention with acupuncture and those who undergo a placebo intervention obtain the same results. Likewise, the percentage of patient withdrawal prior to trial termination is similar in both groups (acupuncture and placebo). This negative finding is of the utmost interest, since fibromyalgia is a condition that entails a high degree of physical disability for sufferers, so that they tend to display a high degree of adherence to any type of intervention which promises to bring about even a minimal improvement in their symptomatology.

Treatment of pain is one of the main therapeutic uses of acupuncture, yet systematic reviews have highlighted the fact that there is considerable variability in outcomes 
Table 1. Characteristics of Included Studies (w: week)

\begin{tabular}{|c|c|c|c|c|c|}
\hline \multirow{2}{*}{ Study } & \multicolumn{2}{|c|}{ N (Women) } & \multicolumn{2}{|c|}{ Intervention } & \multirow[t]{2}{*}{ Current Treatments } \\
\hline & $\begin{array}{l}\text { Active } \\
\text { Group }\end{array}$ & $\begin{array}{l}\text { Sham } \\
\text { Group }\end{array}$ & Technique & Treatment & \\
\hline $\begin{array}{l}\text { Lautenschlager, } \\
1989\end{array}$ & $\begin{array}{c}17 \\
(17)\end{array}$ & $20(18)$ & $\begin{array}{l}\text { Electroacupuncture } v s \text { placebo } \\
\text { treatments with a disconnected } \\
\text { laser equipment }\end{array}$ & 6 treatments & \\
\hline Deluze, 1992 & $\begin{array}{c}36 \\
(33)\end{array}$ & $34(21)$ & $\begin{array}{l}\text { - } \quad \text { 4-10 stainless steel needles }(0.3-22 \\
\text { mm). Depth: } 10-25 \mathrm{~mm} \\
\text { - } \\
\text { Electrostimulator ( } 5 \text { pairs of } \\
\text { electrodes). } 1-99 \mathrm{~Hz} \text { (frecuency), } \\
10 \mathrm{~mA} \text { (max. intensity). } \\
\text { - } \quad \text { Electrostimulation in common } \\
\text { acupuncture points } v s \\
\text { electrostimulation } 20 \mathrm{~mm} \text { away } \\
\text { from these points. }\end{array}$ & $\begin{array}{l}6 \text { sessions }(2 \text { sessions / } \mathrm{w} \\
\text { during } 3 w)\end{array}$ & $\begin{array}{c}\text { Any other usual treatments: } \\
\text { physiotherapy, analgesics, anti- } \\
\text { inflammatory agents, tricyclic } \\
\text { antidepressants. }\end{array}$ \\
\hline Sprott, 1998a & 10 & 10 & $\begin{array}{l}\text { - Acupuncture points according to } \\
\text { the rules and nomenclature of } \\
\text { Traditional Chinese Medicine } \\
\text { - Acupuncture treatments } v s \text { sham } \\
\text { treatments (disconnected laser } \\
\text { equipment) }\end{array}$ & $\begin{array}{l}\quad 6 \text { treatments } \\
(2 \text { treatments } / \text { w during } 3 w)\end{array}$ & 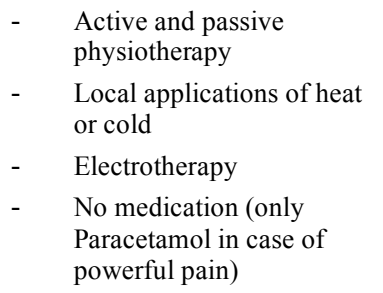 \\
\hline Assefi, 2005 & $\begin{array}{c}25 \\
(22)\end{array}$ & $71(69)$ & $\begin{array}{l}\text { Directed acupuncture according to } \\
\text { the practice of Traditional Chinese } \\
\text { Medicine } v s 1 \text { of } 3 \text { sham } \\
\text { acupuncture treatments: } \\
\text { acupuncture for an unrelated } \\
\text { condition, needle insertion at } \\
\text { nonacupoint locations, or } \\
\text { noninsertive simulated } \\
\text { acupuncture. } \\
\text { Time of needle insertion ( } 30-40 \\
\text { gauge): } 30 \text { min./acupoint }\end{array}$ & 2 treatment $/ \mathrm{w}$ during $12 \mathrm{w}$ & $\begin{array}{l}\text { Any usual fibromyalgia-related } \\
\text { pharmacologic and non- } \\
\text { pharmacologic therapies without } \\
\text { additional changes }\end{array}$ \\
\hline Harris, 2005 & $\begin{array}{c}29 \\
(29)\end{array}$ & $28(24)$ & $\begin{array}{ll}\text { - } & \text { Sterile, } 2.54 \mathrm{~cm} \text {, single-use, } \\
\text { disposable, } 38 \text {-gauge stainless } \\
\text { steel needles } \\
\text { Manual stimulation in traditional } \\
\text { needle locations } v s \text { manual } \\
\text { stimulation in non traditional } \\
\text { needle locations }\end{array}$ & $\begin{array}{c}-\quad 3 \mathrm{w}: 1 \text { treatment } / w \\
-\quad 3 \mathrm{w}: 2 \text { treatment } / w \\
-\quad 3 \mathrm{w}: 3 \text { treatment } / w \\
\text { 2w washout period between } \\
\text { each treatment dose }\end{array}$ & $\begin{array}{l}\text { Normal treatment regimen } \\
\text { without additional changes }\end{array}$ \\
\hline Martin, 2006 & $\begin{array}{l}25 \\
(25)\end{array}$ & $25(24)$ & $\begin{array}{l}\text { - } 18 \text { needle during the first } 3 \\
\text { sessions and } 20 \text { needles during the } \\
\text { final } 3 \text { sessions } \\
\text { - Electrical stimulation (frequency: } \\
1-10 \mathrm{~Hz} \text { ) in traditional points } v s \\
\text { sham stimulation with modified } \\
\text { acupuncture needle that looks } \\
\text { identical to the acupuncture } \\
\text { treatment }\end{array}$ & $\begin{array}{c}6 \text { treatment sessions }(1 \\
\text { treatment } / 2 \text { to } 4 \text { days during } \\
2 \text { to } 3 w)\end{array}$ & \\
\hline
\end{tabular}

depending on the pathology involved. For instance, while this technique has shown moderate proof of benefit for neck disorders and lumbar pain [13] -principally in the short termno evidence of benefit was recently found for treatment of shoulder pain. In the case of fibromyalgia, few treatments have been shown to be effective. One exception to this is supervised aerobic-exercise training, which has been reported as having a beneficial effect on the symptoms of this syndrome [5], though more information is currently needed on the long-term benefit to be had from this type of activity. Acupuncture, reviewed at a qualitative level in previous studies, without meta-analysis, displayed positive results when low-quality experimental studies were combined with observational cohort studies [14], but when randomized control trials alone were reviewed, these positive results disappeared [15]. Using meta-analysis, this new study complements previous qualitative studies by furnishing a global quantitative estimator that underscores the ineffectiveness of this intervention for treatment of fibromyalgia.

Attention should be drawn to the fact that in the clinical trials reviewed, not many subjects were lost to the placebo 


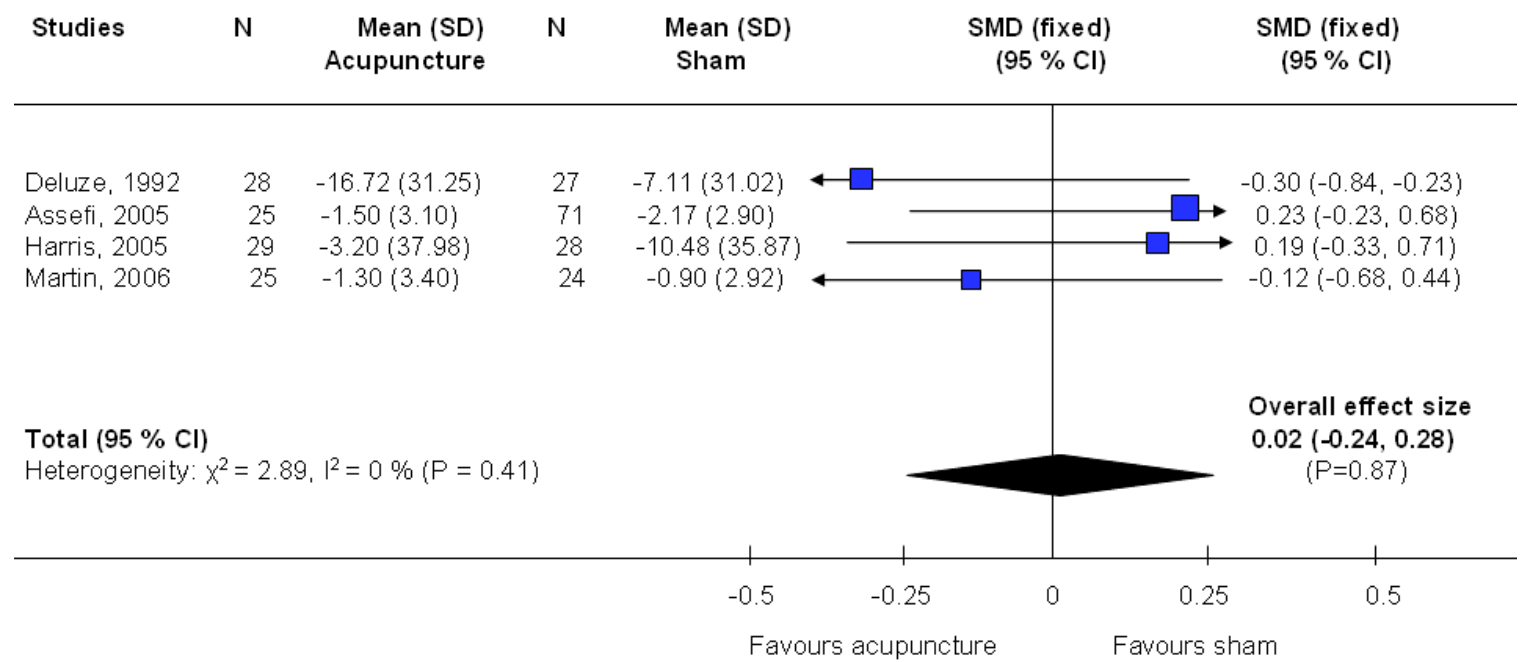

Fig. (2A). Meta-analysis of efficacy: intensity of pain by visual analogue scale (VAS). $S D$ : standard deviation; $C I$ : confidence interval; $S M D$ : standardized mean differences; $P$ : $\mathrm{p}$-value.

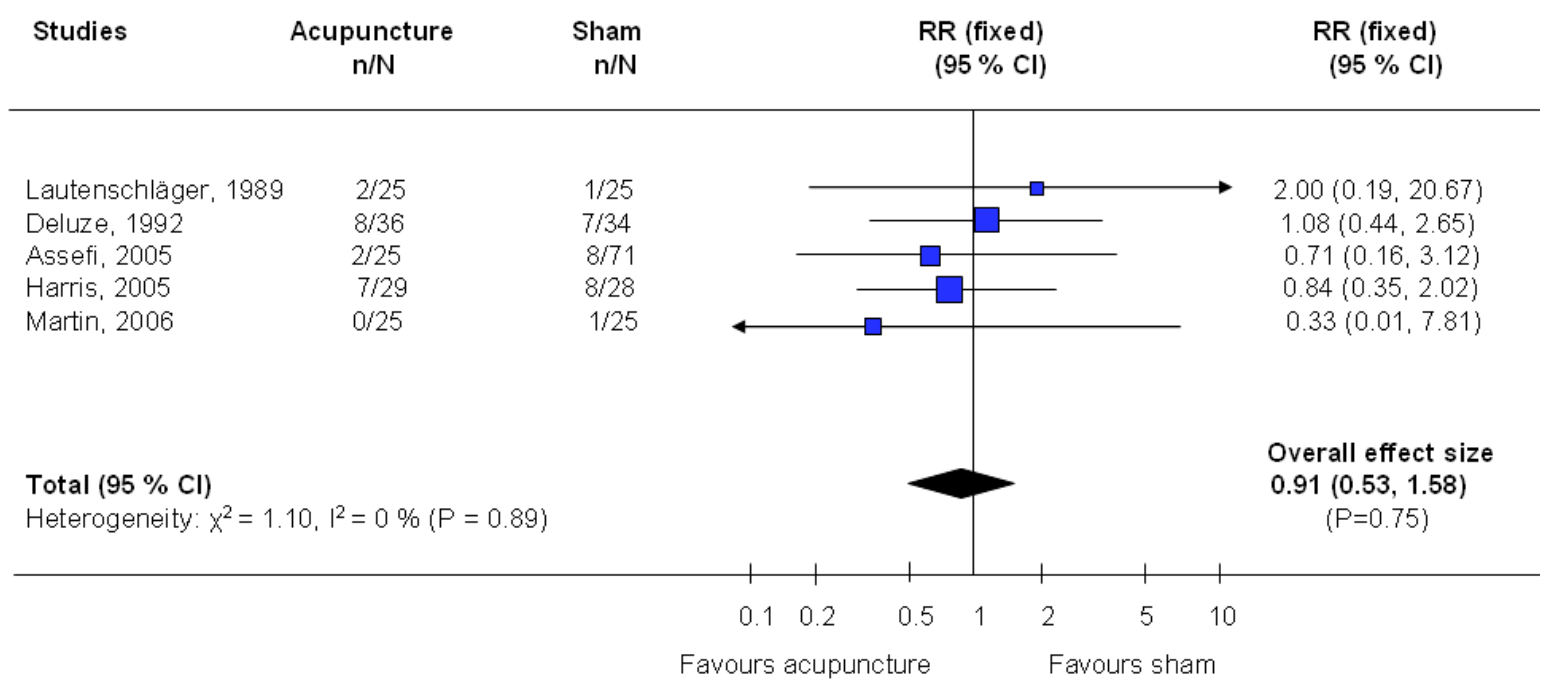

Fig. (2B). Meta-analysis of efficacy: withdrawals for any reason. RR: relative risk; CI: confidence interval; P: p-value.

versus the experimental groups in medium-term studies $(\geq$ 10 weeks) $-29 \%$ versus $24 \%$ and $11 \%$ versus $8 \%$, respectively- which might point to an important placebo effect for this technique. Indeed, one study included in our review even failed to observe differences between groups with correct versus incorrect needle placement [10], yet there was a reduction in intragroup pain intensity across all study groups. The different withdrawal percentages observed between short- and long-term studies might be due to the fact that subjects were kept on their usual medication during the trial, thus making for few withdrawals in the short term and an increase in withdrawals with time.

\section{ACKNOWLEDGEMENTS}

We should like to thank: José Manuel Estrada for his collaboration in the bibliographic search and Michael Benedict for his assistance with the editing.

\section{FUNDING/SUPPORT}

This study was partially funded by Carlos III Institute of Health (Project $n^{\circ}$ PI05/90170). No funding was received from pharmaceutical industries.

\section{REFERENCES}

[1] Wolfe F. Pain extent and diagnosis: development and validation of the regional pain scale in 12,799 patients with rheumatic disease. J Rheumatol 2003; 30(2): 369-78.

[2] Fietta P, Fietta P, Manganelli P. Fibromyalgia and psychiatric disorders. Acta Biomed 2007; 78(2): 88-95.

[3] Goldenberg DL, Burckhardt C, Crofford L. Management of fibromyalgia syndrome. JAMA 2004; 292(19): 2388-95.

[4] Busch AJ, Schachter CL, Overend TJ, Peloso PM, Barber KA Exercise for Fibromyalgia: A systematic review. J Rheumatol 2008; 35 (6): 1130-44

[5] O'Malley PG, Balden E, Tomkins G, Santoro J, Kroenke K, Jackson JL. Treatment of fibromyalgia with antidepressants: a meta-analysis. J Gen Intern Med 2000; 15(9): 659-66.

[6] Ezzo J, Berman B, Hadhazy VA, Jadad AR, Lao L, Singh BB. Is acupuncture effective for the treatment of chronic pain? A systematic review. Pain 2000; 86(3): 217-25.

[7] Lautenschläger J, Schnorrenberger CC, Müller W. Acupuncture with general fibromyalgia syndrome. Dtsch Zschr Akup 1989; 32: 122-8.

[8] Sprott H. Efficiency of acupuncture in patients with fibromyalgia Clin Bull Myofascial Ther 1998; 3 (1): 37-43.

[9] Deluze C, Bosia L, Zirbs A, Chantraine A, Vischer TL. Electroacupuncture in fibromyalgia: results of a controlled trial. BMJ 1992; 305(6864): 1249-52 
[10] Harris RE, Tian X, Williams DA, et al. Treatment of fibromyalgia with formula acupuncture: investigation of needle placement, needle stimulation, and treatment frequency. J Altern Complement Med 2005; 11(4): 663-71.

[11] Assefi NP, Sherman KJ, Jacobsen C, Goldberg J, Smith WR, Buchwald D. A randomized clinical trial of acupuncture compared with sham acupuncture in fibromyalgia. Ann Intern Med 2005; 143(1): 10-9.

[12] Martin DP, Sletten CD, Williams BA, Berger IH. Improvement in fibromyalgia symptoms with acupuncture: results of a randomized controlled trial. Mayo Clin Proc 2006; 81(6): 749-57.
[13] Wang SM, Kain ZN, White PF. Acupuncture analgesia: II. Clinical considerations. Anesth Analg 2008; 106(2): 611-21.

[14] Berman BM, Ezzo J, Hadhazy V, Swyers JP. Is acupuncture effective in the treatment of fibromyalgia? J Fam Pract 1999; 48(3): 213-8.

[15] Mayhew E, Ernst E. Acupuncture for fibromyalgia--a systematic review of randomized clinical trials. Rheumatology (Oxford) 2007; 46(5): 801-4.

Received: February 27, 2009

Revised: March 20, 2009

Accepted: June 3, 2009

(C) Martin-Sanchez et al.; Licensee Bentham Open.

This is an open access article licensed under the terms of the Creative Commons Attribution Non-Commercial License (http://creativecommons.org/licenses/by-nc/

3.0/) which permits unrestricted, non-commercial use, distribution and reproduction in any medium, provided the work is properly cited. 